This is the author's version of the work. It is posted here by permission of the AAAS for personal use, not for redistribution. The definitive version was published in Science vol 354 , pp. 1529-1530, December 23, 2016. DOI: 10.1126/science.aaj232.

\title{
Oceans on the edge of anoxia
}

Andrew J Watson, College of Life and Environmental Sciences, University of Exeter, UK

For the past several hundred million years, oxygen concentrations in Earth's atmosphere have been comparatively high $(1,2)$. Yet, the oceans seem never to have been far from anoxia (oxygen depletion) and have occasionally suffered major oceanic anoxic events (OAEs), recognized in the rock record through accumulations of dark, organic-rich shales (3). OAEs seem to be promoted by warm climates, and some have been associated with major environmental crises and global-scale disturbances in the carbon cycle. New insights into the causes of OAEs are now emerging $(4,5)$. Furthermore, ocean oxygen concentrations are declining in the modern ocean (6). A full-scale OAE would take thousands of years to develop, but some of today's processes are reminiscent of those thought to have promoted OAEs in the distant past.

Even today, the oceans are on the edge of anoxia: Every ocean basin has an oxygen minimum zone (OMZ) at a depth of a few hundred meters, where respiration consumes oxygen and depresses oxygen concentrations. Over large areas of the Eastern Pacific and the northern Indian Ocean, oxygen levels in the $\mathrm{OMZ}$ are close to zero. In modern times, some OMZs have expanded, a process called ocean deoxygenation (6). In addition, nutrient input from rivers has led to eutrophication and local anoxia in many coastal regions. An example of these "dead zones" is the Gulf of Mexico near the Mississippi Delta, but there are now several hundred anoxic coastal regions worldwide. Mostly, these are the result of human activities that have led to much-increased nutrient levels in rivers.

Why is the deep ocean deoxygenating? Human-caused eutrophication may be a contributing factor, but climate change is also implicated. Warming promotes deoxygenation because it slows the formation of deep waters and decreases the solubility of oxygen in the surface. At a recent discussion meeting at the Royal Society in London, all these possible causes were discussed (7). Yet, none of them seems to fully explain the observed declines in oxygen, especially those seen in the tropical oceans.

As to the persistence of OMZs in the oceans past and present, a simple calculation, first made by Alfred Redfield (8), suggests that the global ocean is chronically close to the edge of anoxia. When water leaves the sea surface, it carries oxygen absorbed from the atmosphere into the interior. An equivalent volume of deep water must upwell to the surface, carrying the limiting nutrient phosphate up from the deep ocean.

(The deep waters must also carry up nitrate, but geochemists think of phosphate as the limiting nutrient because nitrogen can always be fixed by plankton from the atmosphere if it is in short supply.) Photosynthetic plankton then use up all the nutrients in the upwelling water, and the fixed organic matter sinks into the deep sea. There, it is respired back into inorganic carbon and nutrients by microbes, in the process consuming the oxygen supplied by the sinking water. Using the stoichiometry of carbon and nutrients now called the "Redfield ratios," Redfield found that the amount of oxygen consumed is almost equal to that carried down by the sinking water (8).

The oxygen demand in the interior of the modern ocean is thus constrained to be close

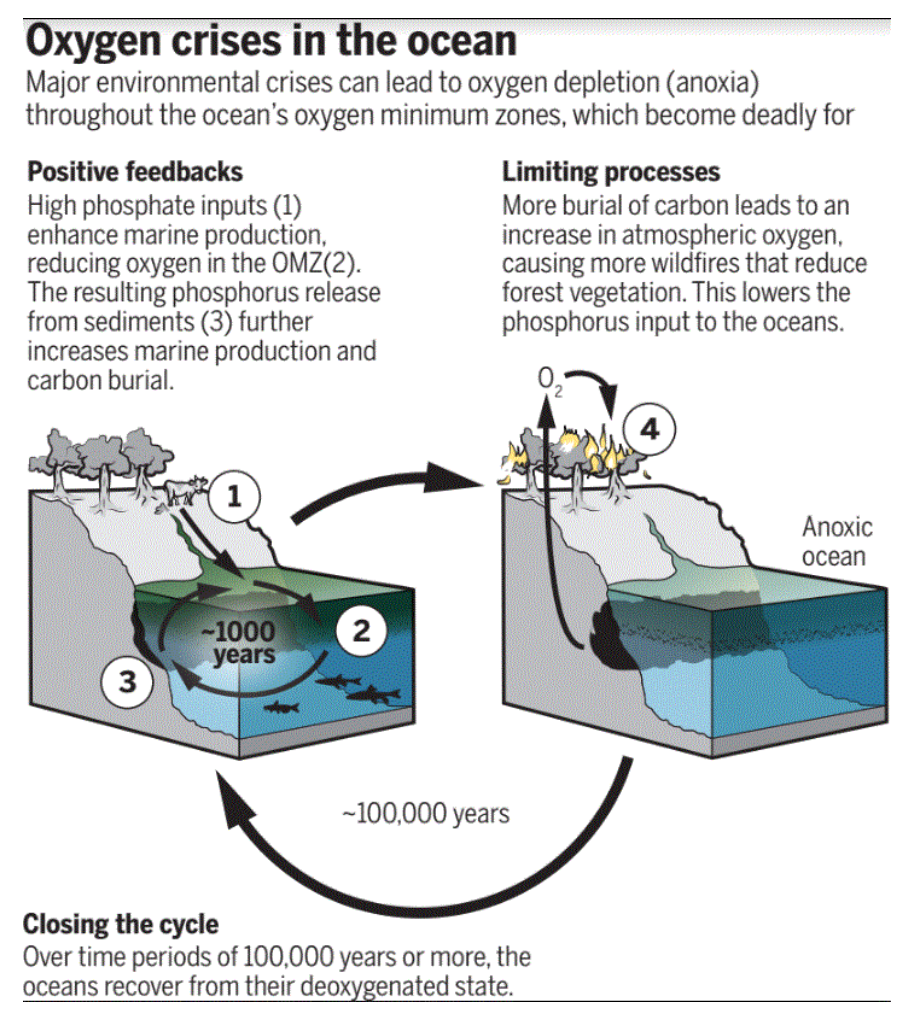

en depletion (anoxia)

\section{Positive feedbacks}

igh phosphate inputs (1)

The resulting phosphorus release carbon buria 
to the oxygen supply. This near-equality seems paradoxical because demand and supply are set by two apparently independent variables: Demand is governed by the amount of phosphate in the deep ocean, whereas the supply is set by the amount of atmospheric oxygen that dissolves in surface water. A little more phosphate, and much more of the ocean would be hypoxic (low in oxygen). Doubling ocean phosphate would be sufficient to bring on a full-scale ocean anoxic event.

Past natural events are believed to have suddenly increased the supply of phosphorus, especially the massive outpourings of magma that form large igneous provinces (LIPs). Prominent OAEs occurred at the same time as, or very shortly after, the eruption of $\operatorname{LIPs}(4,5,9,10)$. A possible mechanism is that the fastweathering rocks emplaced by these events increase the supply of nutrients to the oceans for thousands of years, forcing the ocean into anoxia.

Once anoxia takes hold, it may be self-sustaining. Phosphorus is removed from the ocean through sedimentation, but if anoxic waters overlay these sediments they tend to leach out much of this phosphorus; in contrast, if the water is oxygenated the phosphorus stays in the sediments. Sediments in contact with anoxic water are thus an inefficient phosphorus sink and may even be a source of phosphorus to the ocean. Models suggest that once anoxia begins to spread over continental shelves and slopes, this positive feedback may drive the ocean into prolonged deoxygenation that lasts hundreds of thousands of years (see the figure) $(11,12)$.

Since the industrial revolution, land-use changes, agricultural runoff, and sewage discharges have more than doubled the amount of phosphorus entering the ocean via rivers (13). The coastal dead zones that have developed as a result are often lethal to animal life. However, the increase in nutrient input would need to be sustained for at least a thousand years to produce a change in phosphate levels sufficient to bring on a full-scale OAE. Whole-ocean anoxia is thus not an immediate global concern. If sustained for long enough, the deoxygenation occurring today could nevertheless have lasting negative consequences for the global environment.

On yet longer time scales, the paradox noted by Redfield may be explained by another feedback. A sustained increase in phosphate entering the ocean would increase not only anoxia but also marine productivity, causing more carbon to be buried in sediments. Carbon burial is the source of free oxygen because burial is the only process by which photosynthetically fixed carbon can escape reoxidation on a geologically short time scale. The resulting atmospheric oxygen increase would start to be significant on time scales of 100,000 years or more, eventually alleviating the ocean anoxia (see the figure). Rising molecular oxygen might also limit forest vegetation on land because of the increased prevalence of wildfire; given that forests increase the rates of weathering of continental rocks, limiting them would provide a negative feedback on the supply of phosphorus to the oceans, bringing the system back to a new steady state (14).

Atmospheric oxygen and ocean phosphorus are thus linked in a network of multiple feedback loops. Negative feedbacks help to explain the longevity and stability of atmosphere and ocean composition, but some feedbacks are of opposite sign and may at times destabilize the Earth system, as during OAEs. The role of these positive feedbacks in sustaining OAEs remains an open question, however, as does a complete description of the underlying causes of modern-day deoxygenation; conceivably, natural feedbacks may act to amplify the effects of global change on ocean oxygen concentrations.

\section{References}

$\triangleleft$ B. J. W. Mills et al., Geology 44, 1023 (2016).Abstract/FREE Full Text

$\leftrightarrow$ I. J. Glasspool et al., Nat. Geosci. 3, 627 (2010).CrossRefGeoRef

$\triangleleft$ H. C. Jenkyns, Geochem. Geophys. Geosyst. 11, Q03004 (2010).

$\triangleleft$ L. M. E. Percival et al., Geology 44, 759 (2016).Abstract/FREE Full Text

$\triangleleft$ L. M. E. Percival et al., Earth Planet. Sci. Lett. 428, 267 (2015), 
4 IPCC, Climate Change 2013: The Physical Science Basis. Working Group I Contribution to the Fifth Assessment Report of the Intergovernmental Panel on Climate Change, T. F. Stocker et al., Eds. (Cambridge Univ. Press, Cambridge, 2013).

4

"Ocean ventilation in a warming world," Meeting at the Royal Society of London, 12 to 13 September 2016,

J. G. Shepherd, A. J. Watson, A. Oschlies, P. Brewer, Conveners.

$\triangleleft$ A. C. Redfield, Am. Sci. 46, 205 (1958).GeoRefWeb of Science

$\triangleleft$ B. Sell et al., Earth Planet. Sci. Lett. 408, 48 (2014).

$\triangleleft$ S. C. Turgeon et al., Nature 454, 323 (2008).CrossRefGeoRefMedlineWeb of Science

$\leftrightarrow$ I. C. Handoh, T. M. Lenton, Global Biogeochem. Cycles 17, 1092 (2003).CrossRef

$\triangleleft$ K. Ozaki et al., Earth Planet. Sci. Lett. 304, 270 (2011).

$\triangleleft$ F. T. Mackenzie et al., Chem. Geol. 190, 13 (2002).CrossRefGeoRefWeb of Science

$\triangleleft$ N. M. Bergman et al., Am. J. Sci. 304, 397 (2004).Abstract/FREE Full Text 